\title{
Joining the Conversation:
}

\section{A Commentary on Glăveanu's Critical Reading}

\author{
James C. Kaufman
}

University of Connecticut, USA

E-mail: james.kaufman@uconn.edu

ARTICLE INFO

\section{Keywords:}

Collaboration

Dialogue

Article history:

Received 24 October 2014

Received in revised form 19 December 2014

Accepted 20 December 2014

ISSN: 2354-0036

DOI: 10.15290/ctra.2014.01.02.07
A B S T R A C T

In this commentary, I add my thoughts to Glăveanu's excellent target article. I add two points to move the dialogue forward. One point is that although as a field we do have our portion of the blame, other disciplines must also share the burden. When new areas "discover" creativity they often begin anew, or claim there is no consensus, or else start and end with Guilford and Torrance. However, my second point is that the answer, to me, is via collaboration and dialogue. The people who are "scholarly bilingual" - who "speak" creativity jargon but also understand the ins and outs of another field - are the keys. Conversations and collaborations can help advance the field.

I'm delighted to get a chance to comment on the excellent and provocative paper by Vlad Glăveanu (2014). Many of the issues he raises are ones I have addressed in other works (such as the Four-C theoretical work with Ronald Beghetto; Kaufman \& Beghetto, 2009, 2013). But Glăveanu takes pain to emphasize that he is making a selective review of the literature, and I don't intend this commentary to be a standard "look at the work I've done that isn't cited!" piece.

Instead I want to suggest two additional principles that he alludes to in the text. One is hinted at when he cites Plucker, Beghetto and Dow's (2004) exploration of why creativity doesn't play a bigger role in educational psychology. Glăveanu correctly places some of the blame at our feet - which I accept - but I also contend that when other fields "discover" the concept of creativity, they rarely do their homework in the slightest - or else they stop in the 1960's. As Cropley (in press) notes, when engineers (among many other disciplines) decide to study creativity they broadly announce that there is no acceptable definition or consensus about what it is - which is, of course, nonsense. Whether or not our standard definition is flawed (it is), could stand to be challenged (it could), or is hard to implement (it might be), there's a striking agreement about the basics of what creativity is. When other areas (which includes my "home field" of psychology - 
there are many papers published on creativity in top journals by experts in other subdisciplines) study creativity, they must avoid wallowing in the same hackneyed myths that Plucker et al. (2004) outline.

As a second added principle, however, we must actively seek out related work. Glăveanu himself is one of the masters of this effort to incorporate the research of related fields. Whether it is called imagination, improvisation, innovation, or something else, creativity or some related facet is studied in numerous other fields, yet there is strikingly little communication. My colleagues and I have tried to address this gap (e.g., Reiter-Palmon, Beghetto, \& Kaufman, 2013), but we are a drop in the ocean. There are several scholars out there whom I call scholarly bilingual - they speak "creativity" but other fields also speak. My friends and colleagues Oshin Vartanian, Roni Reiter-Palmon, and David Cropley are just a few that quickly come to mind, who can translate the jargon of neuroscience, business, and engineering research (respectively) into creativity-speak.

One of the goals of my career has been to get people to speak to each other. I grew up as the child of IQ test developers (indeed, I still am) and it struck me, when I much later took cognitive psychology classes, how many basic questions could be (and were) answered with IQ test data. Cognitive psychologists often looked down on IQ test developers (too much money involved) and would in the process over-value their studies with a sample of 40 college students and under-value or ignore the normative studies of IQ tests with very similar tasks that had samples in the thousands. I am scared that we are doing this exact same thing in creativity - overlooking essential work in organizational psychology that could be applied to the classroom, or vice versa.

The best way to solve this dilemma is with dialogue and connections. Glăveanu has started many dialogues - including this one - and is as excited as I am about connecting different disciplines, cultures, domains and methodologies. I have only tackled a fraction of the issues he has raised, and I look forward to seeing how other commentaries engage in this dialogue - and, even more, continuing these conversations outside of the written page and at conventions, visits, and Skype talks!

\section{REFERENCES}

Cropley D.A. (in press). Teaching engineers to think creatively: Barriers and challenges in

STEM disciplines. To appear in R. Wegerif, L.Li, \& J.C. Kaufman (Eds.), The Routledge international handbook of research on teaching thinking. London: Routledge.

Glăveanu, V.P. (2014). The psychology of creativity: A critical reading. Creativity:

Theories - Research - Applications, 1, 10-32, DOI: 10.15290/ctra.2014.01.01.02. 
Kaufman, J.C. \& Beghetto, R.A. (2009). Beyond big and little: The Four C Model of Creativity. Review of General Psychology, 13, 1-12.

Kaufman, J.C., \& Beghetto, R.A. (2013). In praise of Clark Kent: Creative metacognition and the importance of teaching kids when (not) to be creative. Roeper Review, 35, 155-165

Plucker, J.A., Beghetto, R.A., \& Dow, G.T. (2004). Why isn't creativity more important to educational psychologists? Potentials, pitfalls, and future directions in creativity research. Educational Psychologist, 39, 83-96.

Reiter-Palmon, R., Beghetto, R.A., \& Kaufman, J.C. (2014). Looking at creativity through a Business-Psychology-Education (BPE) lens: The challenge and benefits of listening to each other. In E. Shiu (Ed.), Creativity research: An interdisciplinary and multidisciplinary research handbook (pp. 9-30). New York: Routledge.

Corresponding author at: James C. Kaufman, University of Connecticut, Neag School of Education, 2131 Hillside Road, Storrs, CT, 06269-3007.

E-mail: james.kaufman@uconn.edu 